\title{
Impact of application of biochar and biochar-based fertilizer on peanuts nutrient absorption and yield
}

\author{
GAO Mengyu ${ }^{1,2, a}$, YANG Jinfeng ${ }^{1,2, b^{*}}$, \\ Du Zhide ${ }^{1,2, \mathrm{c}}$, Mu Jiahui ${ }^{1,2, \mathrm{~d}}$, Zhang Yahao ${ }^{1,2, \mathrm{e}}$

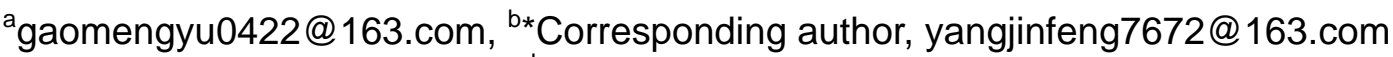 \\ c2264582782@qq.com, d793024240@qq.com, e865132744@qq.com \\ ${ }^{1}$ College of Land and Environment, Shenyang Agricultural University, Shenyang 110866, China \\ ${ }^{2}$ National Engineering Laboratory of High Efficient Use on Soil and Fertilizer Resources
}

Keywords: biochar, biocahr-based fertilizer, nutrient absorption, yield, peanuts

\begin{abstract}
The object of this study was to investigate application of biochar and biochar-based fertilizer on the peanuts content of nutrient absorption and yield. The results showed that applying biochar-based fertilizer can improve nitrogen, phosphorus and potassium absorbed dose. In comparison with the lower level of carbon treatment, the higher one nitrogen absorbed dose was obviously increase by $14.62 \%$. In application of biochar-based fertilizer and chemical fertilizer can improve phosphorus absorption significantly compared with carbon alone applied. The potassium absorption content of biochar-based fertilizer (BBF) treatment was the most and increased by 28.39\% and $17.47 \%$ in comparison with NPK treatment and C15 treatment, respectively. Peanut yield was the highest when biochar-based fertilizer was used. It reached $3494 \mathrm{~kg} / \mathrm{hm}^{2}$ and higher than application of the same level of carbon and nutrient treatment by $16.8 \%, 9.80 \%$, respectively.
\end{abstract}

\section{Introduction}

Biochar contains a large amount of carbon-containing substances and is manufactured by the thermal cracking of biomass such as agricultural and forestry wastes in oxygen-deficient conditions [1]. It has high carbon content, abundant soil pore space, a large specific surface area, and stable physical and chemical properties [2]. It's helpful to soil nutrient fixation and the improvement of nutrient utilization rate $[3,4]$. Biochar-based fertilizer is an exclusive slow-release complex fertilizer, which is produced by the incomplete combustion of fodder, corncobs, peanut shells, and agricultural in anaerobic conditions with an admixture of different proportions of nutrients [5]. Zhao's [6] research showed that compared with chemical fertilization treatment, combined application of organic and inorganic fertilizer with biochar effectively increased the content of total nitrogen and potassium, available nitrogen, potassium and phosphorus. Zhang [7] detected that biochar additions significantly enhanced the yield and quality of soybean. As a result, this study in order to investigate the effect of peanuts nutrient absorption and yield in brown soil when biochar-based fertilizer was used and provided a theoretical basis for improving nutrient utilization rate to make a rational use of biochar and biochar-based fertilizer.

\section{Materials and methods}

The long-term experiment was located in Liaoning Province at the Shenyang Agricultural University Peanut Scientific Research Center $\left(40^{\circ} 48^{\prime} \mathrm{N}, 123^{\circ} 33^{\prime} \mathrm{E}\right)$. The soil at the experimental site was a brown soil classified as an alfisol, with hydromica as a dominant clay mineral. This experiment began in 2011 and the basic physical and chemical properties are detailed in Table 1.

Table 1 Basic properties of soil at the beginning of the experiment

\begin{tabular}{ccccccccc}
\hline $\begin{array}{c}\text { Soil } \\
\text { layer } \\
(\mathrm{cm})\end{array}$ & $\begin{array}{c}\text { Organic } \\
\text { matter } \\
(\mathrm{g} / \mathrm{kg})\end{array}$ & $\begin{array}{c}\text { Total N } \\
(\mathrm{g} / \mathrm{kg})\end{array}$ & $\begin{array}{c}\text { Total P } \\
(\mathrm{g} / \mathrm{kg})\end{array}$ & $\begin{array}{c}\text { Total K } \\
(\mathrm{g} / \mathrm{kg})\end{array}$ & $\begin{array}{c}\text { Available } \\
(\mathrm{mg} / \mathrm{kg})\end{array}$ & $\begin{array}{c}\text { Available } \\
\mathrm{P} \\
(\mathrm{mg} / \mathrm{kg})\end{array}$ & $\begin{array}{c}\text { Available } \\
\mathrm{K} \\
(\mathrm{mg} / \mathrm{kg})\end{array}$ & $\mathrm{pH}$ \\
\hline $0-20$ & 13.1 & 0.53 & 0.67 & 18.8 & 56.2 & 12.5 & 89.6 & 6.81 \\
\hline
\end{tabular}

Five treatments (three replicates each) were established in 2011 and end in 2014. There were 5 
treatments: no fertilization (CK), low levels of biochar (C15, $\left.225 \mathrm{~kg} / \mathrm{hm}^{2}\right)$, high levels of biochar (C50, $750 \mathrm{~kg} / \mathrm{hm}^{2}$ ), chemical fertilizer (NPK, $82.5 \mathrm{~kg} / \mathrm{hm}^{2} \mathrm{~N}, 82.5 \mathrm{~kg} / \mathrm{hm}^{2} \mathrm{P}_{2} \mathrm{O}_{5}$, and 97.5 $\mathrm{kg} / \mathrm{hm}^{2} \mathrm{~K}_{2} \mathrm{O}$ ), and biochar-based fertilzier (BBF, C 6.6\%, N-P $\mathrm{O}_{5}-\mathrm{K}_{2} \mathrm{O} 11-11-13,750 \mathrm{~kg} / \mathrm{hm}^{2}$ ). The carbon content with BBF treatment was the same as with C15 treatment and the NPK number with BBF treatment was the same as with NPK treatment.

The content of nitrogen, phosphorus and potassium absorption determination was semi-micro Kjeldahl determination, vanadium platinum yellow colorimetric method and flame spectrophotometry, respectively. Microsoft Excel 2010 and SPSS 19.0 were used for the statistical analysis of the experimental data.

\section{Results and discussion}

3.1 The nitrogen absorption of different peanuts organ on applying different fertilizer

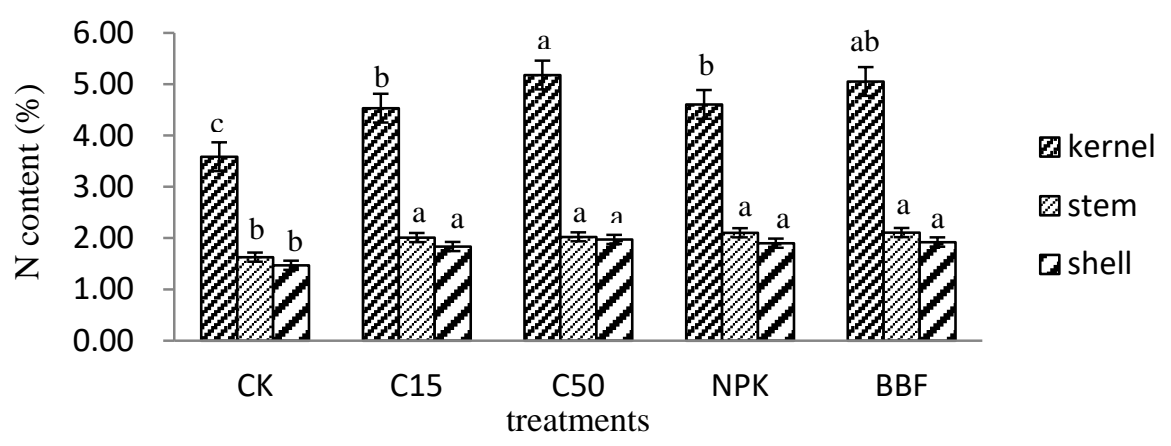

Fig. 1 the content of different peanuts organ absorb $\mathrm{N}$

Different letters represent significant differences between different treatments ( $\mathrm{p}<0.05$;Duncan's test)

The nitrogen is the basic nutrient matter of plants [8]. From figure1, no matter what kind of fertilizer applied in, the content of kernel nitrogen absorption would be higher than CK treatment. The kernel nitrogen absorbed dose was the highest when high level carbon (C50) was used and increased by $14.26 \%$ compared with C15 treatment. The result was as same as Kang's [9]. The second most abundant was BBF treatment and the absorption content increased by $11.44 \%$ and $9.70 \%$ in comparison with C15 and NPK treatment, respectively. They had significant difference. Therefore, biochar-based fertilizer can increase peanuts kernel nitrogen absorption and its effect was greater than that of the same level of carbon or t nutrition treatment. The result as same as Peng's [10].The reason may be biochar carbon can improve soil nitrification rate and the transition of nitrogen [11].

As for the content of stem and shell nitrogen absorption, their regular was same. In comparison with CK, nitrogen absorbed dose was significantly increased by $23.00 \%, 24.31 \%, 29.15 \%, 29.45 \%$ with the application of C15, C50, NPK and BBF respectively.

3.2 The phosphorus absorption content of different peanuts organ

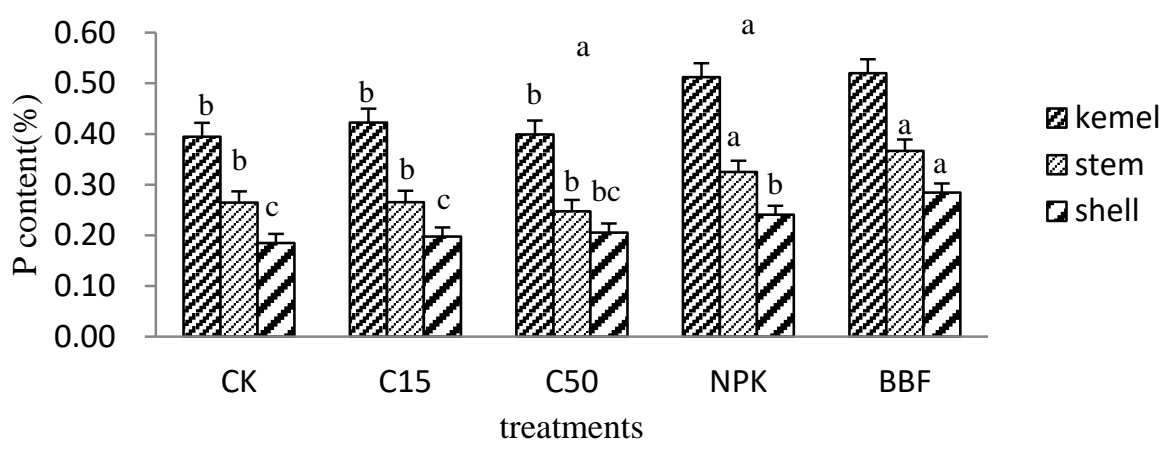

Fig.2 Change in peanuts P content on applying different fertilizer 
The phosphorus was the main factor of soil fertility and the major element in crop growing [12]. The content of phosphorus absorbed by kernel was higher than stem and shell. The peanuts phosphorus absorption was the most with the application biochar-based fertilizer no matter in kernel, stem or shell. In kernel and stem, phosphorus absorbed dose was little lower than BBF treatment by $1.96 \%$ and $15.63 \%$ when NPK was used. There was no significant difference. However, the content of phosphorus absorption in shell was significantly higher than the same level of nutrition treatments (NPK) by $16.67 \%$ in comparison with applied biochar-based fertilizer in soil. The biochar with many hole provided appropriate environment and spot for microbial decomposition of organic or inorganic phosphorus that can accelerated the turnover rate of phosphorus [13].

3.3 Different peanuts organ potassium absorption content

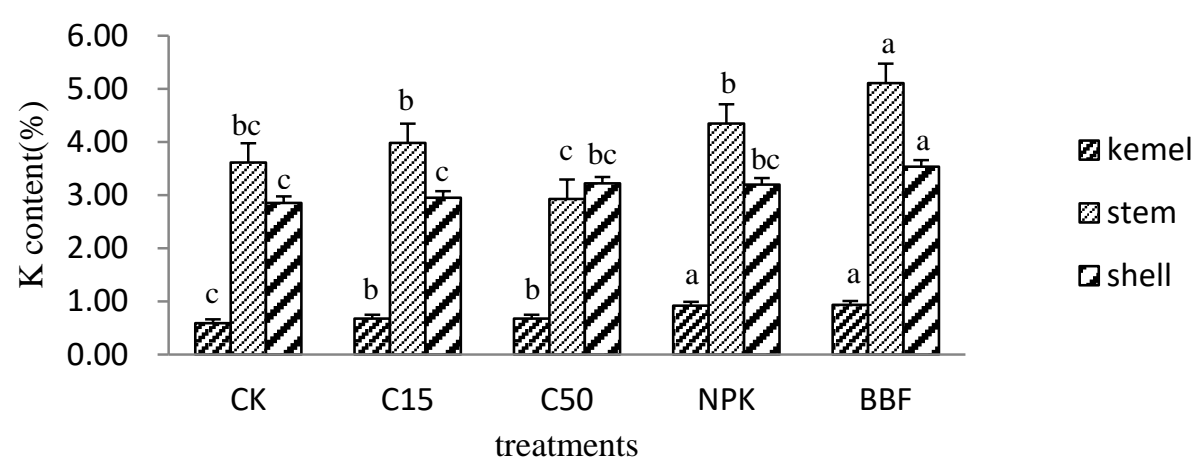

Fig.3 Effects of different treatments on the K content of different peanuts organ

The lack of potassium has been limiting element which influence crop yield and quality [14]. The content of potassium absorbed by stem was the most abundantl. All fertilizer treatment can improve potassium absorption obviously and the effect was better with the application of NPK and biochar-based fertilizer than biochar alone treatments. The content of potassium absorption was $0.92 \%$ and $0.94 \%$ respectively and there was no significant difference. In stem, the absorption content of BBF treatment was the most and increased by $28.39 \%$ and $17.47 \%$ in comparison with NPK treatment and C15 treatment, respectively. The absorption of potassium in shell was highest when biochar-based fertilizer was used and that higher than NPK treatment by $10.63 \%$. They had significant difference.

3.4 Yield

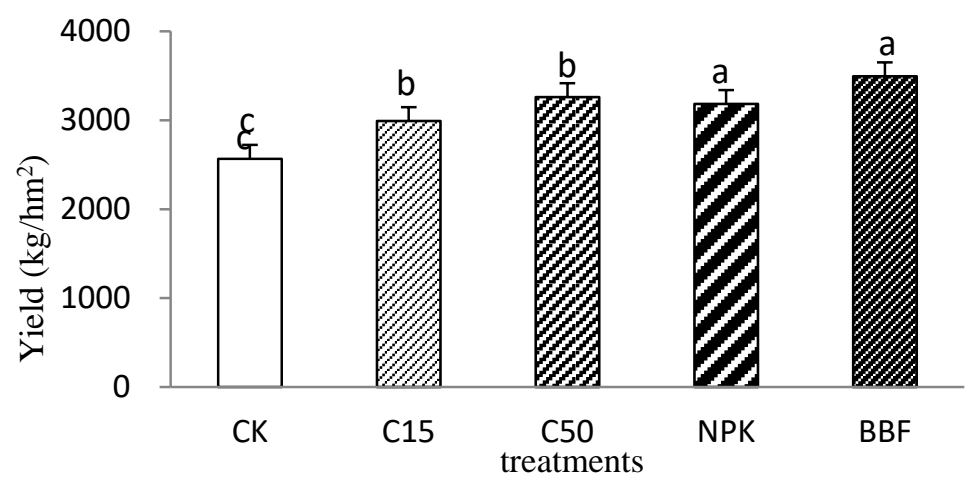

Fig.4 Effect on yield of different fertilization treatments

Peanut yield was different when applied different fertilizer to soil. From figure 4, peanut yield with C15 and C50 treatment was $2566 \mathrm{~kg} / \mathrm{hm}^{2}$ and $22991 \mathrm{~kg} / \mathrm{hm}^{2}$, respectively. Compared to CK treatment respectively increased by $16.6 \%, 27.0 \%$. Application of biochar can significantly improve the peanut production, but the C15 and C50 treatments showed no obvious difference. Peanut yield was the highest when biochar-based fertilizer was used. It reached $3494 \mathrm{~kg} / \mathrm{hm}^{2}$ and higher than application of C15 by $16.8 \%$. At the same level of carbon, biochar-based fertilizer can improve yield significantly. In Comparison with the chemical fertilizer treatment, peanut yield of biochar-based fertilizer treatment increased by $9.8 \%$. However, there was no significance between the same nutrient treatments, biochar-based fertilizer as a new kind of fertilizer as good as chemical fertilizers in the aspect of increasing yield. It can replace the traditional chemical fertilizers in order 
to reduce environmental pressure.

\section{Conclusions}

After long-term fertilization for 4 years, in addition to the application of no fertilizer, after other treatments the content of peanuts nitrogen, phosphorus and potassium absorption were all increased. Compared with the same level of carbon and nutrient treatment, the application of biochar-based fertilizer worked best. The peanut yield with biochar-based fertilizer treatment was the highest. However, there was no significance difference in comparison with the chemical fertilizer treatments.

\section{Acknowledgements}

This study was funded by National Natural Science Foundation of China (41371287) and China Agriculture Research System (CARS-14).

\section{Reference}

[1] Lehmann J, Joseph S, Biochar for environmental management: An introduction. M, In Lehmann J and Joseph S, eds. Biochar for environmental management, science and technology, London: Earths can Publications Ltd, 2009: 1-12.

[2] Cheng C H, Lehmann J, Thies J E, Burton S D, Engelhard M H. Oxidation of black carbon by biotic and abiotic process, J. Organic Geochemistry, 2006, 37(11):1477-1488

[3] Zhang A, Bian R, Hussain Q, Li L, Pan G, Zheng J, Zhang X, Zheng J. Change in net global warming potential of a rice-wheat cropping system with biochar soil amendment in a rice paddy from China, Agriculture, Ecosystems \& Environment, 2013, 17: 37-45.

[4] Zhai L, Cai J Z, Liu J, Wang H, Ren T, Gai X, Xi B, Liu H. Short-term effects of maize residue biochar on phosphorus availability in two soils with different phosphorus sorption capacities, Biol Fert Soils, 2015, 51( 1) :113-122.

[5] Yang J F, Jiang T, Han X R, Li D, Zhang C F, Wang Y, Huang Y Q .Effects of continuous application of biochar-based fertilizer on soil characters and yield under peanuts continuous cropping, J . Soil and Fertilizer Sciences, 2015,03:68-73

[6] Zhang Y Y, Zhang Y P, Liu Q, Rong X M, Xie Y, Chen H R. Effects of organic fertilizer and biochar on soil nutrient accumulation and utilization and Chinese cabbage yield in Dryland, J. Chinese Sci Bull,2016,14:119-125.

[7] Zhang W M, Guan X C, Sun D Q, Men J, Chen W F. Biological effects of corncob-derived biochar on soybean plants, J. Journal of Agro-Environment Science, 2015, 02:391-400.

[8] Güsewell S.N:P ratios in terrestrial plants: variation and functional significance, New Phytologist, 2004,164( 2) : 243-266.

[9] Kang R F, Zhang N M, Shi J, Bao L, Zhang C G, Effects of biochar-based fertilizer on soil fertility, wheat growth and nutrient absorption, J. Soil and Fertilizer Sciences ,2014,06:33-38

[10]Peng H H, Liu Q, Rong X M, Zhang Y P, Tian C, Xie Y. Effects of biochar, organic fertilizer and chemical fertilizer combined application on nutrient utilization and yield of spring maize. $\mathrm{J}$ Guangxi Agricultural Science,2015,46(8):1396-1400

[11]Kookana R S, Sarmah A K, Zwieten L V, Krull E, Singh B .Biochar application to soil: agronomic and environmental benefits and unintended consequences. J, Adv. Agron, 2011, 112:103-143. 
[12]Xiang W S, Huang M, Li X H, Progress on fractioning of soil phosphorous and availability of various phosphorous fractions to crops in soil. J, Plant Nutrition and Fertilizer Science, 2004, 10(6): 663-670

[13]Warnock D D, Lehmann J, Kuyper T W, Rillig M C.Mycorrhizal responses to biochar in soil-concepts and mechanisms. J, Plant Soil, 2007, 300(1):9-20.

[14]Nie X X, Chen F. Advances of the effects of biochar application on soil potassium bioavailability. J, Soil and Fertilizer Sciences, 2016, 02:1-6. 